Article

\title{
Capability Study of Ti, Cr, W, Ta and Pt as Seed Layers for Electrodeposited Platinum Films on $\gamma-\mathrm{Al}_{2} \mathrm{O}_{3}$ for High Temperature and Harsh Environment Applications
}

\author{
Marietta Seifert*, Erik Brachmann, Gayatri K. Rane, Siegfried B. Menzel and Thomas Gemming \\ SAWLab Saxony, IFW Dresden, P.O. Box 270116, 01171 Dresden, Germany; e.brachmann@ifw-dresden.de (E.B.); \\ g.k.rane@ifw-dresden.de (G.K.R.); s.menzel@ifw-dresden.de (S.B.M.); t.gemming@ifw-dresden.de (T.G.) \\ * Correspondence: marietta.seifert@ifw-dresden.de; Tel.: +49-351-4659-639 \\ Academic Editor: Javier Narciso \\ Received: 26 November 2016; Accepted: 5 January 2017; Published: 11 January 2017
}

\begin{abstract}
High temperature surface acoustic wave sensors based on radio frequency identification technology require adequate antennas of high efficiency and thermal stability for the signal transmission. Platinum is well known and frequently used as a material of choice for high temperature and harsh environment applications because of the high melting point and its chemical stability. Therefore, one way to realize high temperature stable antennas is the combination of a Pt metallization on an $\mathrm{Al}_{2} \mathrm{O}_{3}$ substrate. As a cost-effective technique, the $\mathrm{Pt}$ film is deposited via electrochemical deposition. For this growth procedure, a pre-deposited metallization on the $\mathrm{Al}_{2} \mathrm{O}_{3}$ layer is required. This paper analyzes the influence of various seed layers $(\mathrm{Ta}, \mathrm{Ti}, \mathrm{W}, \mathrm{Cr}, \mathrm{Pt})$ on the morphology, stability and electrical properties of the electrochemically-grown Pt thick film after heat treatments up to $1000{ }^{\circ} \mathrm{C}$ in air. We find an oxidation of all adhesion layers except for $\mathrm{Pt}$, for which the best electrical properties were measured. Although significant areas of the films delaminate from the substrate, individual anchor structures retain a stable connection between the Pt layer and the rough $\mathrm{Al}_{2} \mathrm{O}_{3}$ substrate.
\end{abstract}

Keywords: surface acoustic waves; high temperature sensors; planar Pt antenna; electrodeposition; $\mathrm{Al}_{2} \mathrm{O}_{3}$

\section{Introduction}

In recent years, there has been a growing development of Pt-based sensors [1-3], such as temperature sensors, chemical sensors [4] and biological sensors [5,6], because of the outstanding high temperature properties and corrosive resistance of this material. One way to realize such sensors is the surface acoustic wave (SAW) technology, which has been used since more than 30 years for high precision frequency filters [7]. The application of SAW devices for high temperature sensing also combined with radio frequency identification (RFID) has been demonstrated several times [1,8-10]. Such a passive sensor based on SAW technology is composed of a piezoelectric substrate with interdigital transducer electrodes connected to an antenna consisting of a structured metallization on an insulating substrate. All components have to be high temperature stable. In this paper, we focus on the antenna system.

A combination of physical vapor deposition (PVD) processes (especially e-beam deposition) with the lift-off procedure is the standard structuring technique for biological, electrochemical and interdigital transducers [11]. This standard procedure can also be applied for the fabrication of high temperature antennas on rigid high temperature-stable ceramic substrates, such as $\gamma-\mathrm{Al}_{2} \mathrm{O}_{3}$. If a noble metal is deposited on an oxidic substrate, adhesion problems will generally occur because 
of its bad sticking behavior, leading to agglomeration and delamination processes during a heat treatment. A general overview of delamination effects is given, e.g., by Khanna [12]. Classical adhesion layers like titanium that increase the stability of platinum films were described in [13,14]. However, at high temperature and harsh environmental conditions, titanium interacts with platinum, leading to migration and oxidation effects $[15,16]$. For polished $\gamma-\mathrm{Al}_{2} \mathrm{O}_{3}$-substrates and sputtered platinum, the $\mathrm{TiO}_{x}$ adhesion layer has an effect on the texture and the stability of the Pt-film [17]. Interdiffusion between Pt and Ti films under oxygen atmosphere is shown in [18-20]. Tisone and Drobek found diffusion factors of $\mathrm{Ti}$ in $\mathrm{Pt} 10^{5}$-times higher along grain boundaries compared to the bulk value [21].

$\mathrm{Zr}$ and Ti have been used as adhesion layers for platinum metallization, e.g., on smooth sapphire substrates (root mean square roughness $R_{q}=1.3 \pm 0.2 \mathrm{~nm}$ ) [14], polycrystalline alumina oxide (arithmetic average roughness $\left.R_{a}=35 \mathrm{~nm}\right)$ [4,22] or commercial $\mathrm{Si}\left(R_{q}<1 \mathrm{~nm}\right)$ [23].

The above-mentioned results refer to PVD, e.g., sputtered or e-beam deposited, films. An alternative to PVD is the electrochemical deposition or electroplating, which reduces costs compared to standard PVD processes. The biggest benefit compared to PVD processes where a huge amount of material condenses amongst others on the vacuum chamber walls is that the deposition of material only occurs on electrically-conducting surfaces that are in contact with the electrolyte. Especially for expensive materials like platinum or other noble metals, electroplating can be a cost-effective alternative. Therefore, this paper reports on a combination of standard PVD deposition processes for thin seed layers with the low cost electrodeposition technique for the growth of the thick working metallization. The focus is to study the electrochemically-deposited Pt films with the application of various seed (Ti, W, Ta, Cr, Pt) layers. These bilayers are characterized concerning their high temperature stability for application as an antenna system in high temperature SAW sensor devices.

\section{Experimental Section}

All layers were deposited on rectangular $\gamma-\mathrm{Al}_{2} \mathrm{O}_{3}$-substrates (Rubalit 708S, CeramTec GmbH, Marktredwitz, Germany) with a thickness of $0.6 \mathrm{~mm}$ and a surface roughness with maximum values of $R_{a}=600 \mathrm{~nm}$ according to the manufacturer. After cutting the ceramic plates to samples with dimension $24 \mathrm{~mm}$ by $15 \mathrm{~mm}$ the pieces were cleaned in aqua regia at $80^{\circ} \mathrm{C}$ for $1 \mathrm{~h}$ and then boiled two times in deionized water for $1 \mathrm{~h}$. Afterwards the samples were baked in a high temperature oven at $1200{ }^{\circ} \mathrm{C}$ under ambient atmosphere to reduce residual organic contamination by forming gaseous organics. The combination of the wet chemical cleaning process and the high temperature treatment should remove metallic and organic contaminants from the samples surface. The ceramics were removed from the oven at a temperature above $120^{\circ} \mathrm{C}$ and transferred to the device for the deposition of the seed layers. There, a final temperature treatment took place at $500{ }^{\circ} \mathrm{C}$ for $2 \mathrm{~h}$ under high vacuum (HV) atmosphere. The deposition device (CREAMET 350-CL 6, CREAVAC-Creative Vakuumbeschichtung $\mathrm{GmbH}$, Dresden, Germany) with a base pressure below $2 \times 10^{-4} \mathrm{~Pa}$ is evacuated by a combination of Roots pumps (ACP 28, Adixen Pfeiffer Vacuum GmbH, Asslar, Germany) and magnetically levitated turbopumps (TURBOVAC MAG W 600 iP, Oerlikon Leybold Vacuum GmbH, Dresden, Germany).

The nominal necessary film thickness to achieve closed seed layers on polished substrates is about $10 \mathrm{~nm}$. In our case, the substrate roughness is in the same range as the targeted film thickness, hence a seed film thickness of about $100 \mathrm{~nm}$ was chosen. The seed layers also convey the adhesion between the $\mathrm{Pt}$ metallization and the substrate. The $\mathrm{Ti}, \mathrm{W}$, Ta and $\mathrm{Cr}$ seed layers that are investigated in this study are sputter deposited at room temperature at a pressure of $0.18 \mathrm{~Pa}$ by adding $30 \mathrm{sccm}$ Ar sputter gas with a purity of 99.999. The $100 \mathrm{~nm}$ platinum seed layer is electron beam evaporated (EVM-6, FERROTEC GmbH, Untersingen, Germany) in a different chamber of the device at a base pressure of $2 \times 10^{-5} \mathrm{~Pa}$. The e-beam deposition was chosen for Pt since less of this highly expensive material is required for this deposition technique compared to the sputtering. Deposition rates of the PVD-films are summarized in Table 1. Finally, a thick Pt layer was electrodeposited. This galvanic platinum film is indicated as $\mathrm{Pt}^{*}$ in the following. 
Table 1. Deposition rates of the various seed layer materials.

\begin{tabular}{cccccc}
\hline Material & Ti & $\mathbf{C r}$ & $\mathbf{W}$ & $\mathbf{T a}$ & $\mathbf{P t}$ \\
\hline Deposition rate in $\mathrm{nm} / \mathrm{s}$ & 0.27 & 0.3 & 0.18 & 0.49 & 0.1 \\
\hline
\end{tabular}

The seed layer-substrate compounds were stored under high vacuum in the PVD-device until the galvanic deposition process was carried out to prevent oxidation of the materials. To contact the seed layer electrically with a power supply, alligator clamps were directly connected to the metallization. The counter electrode was a circularly curved $\mathrm{Pt}$ sheet. The deposition took place in a $100 \mathrm{~mL}$ beaker filled with $50 \mathrm{~mL}$ commercial platinum electrolyte (Platinbad JE18, C. Jentner GmbH, Pforzheim, Germany), which has a platinum content of $2 \mathrm{~g} / \mathrm{L}$ solved in a $10 \%$ sulfuric acid with a $\mathrm{pH}$ value of 1.5. The solution was convected by a magnetic stirrer at $1200 \mathrm{~min}^{-1}$ on a hotplate with a bath temperature of $30 \pm 1{ }^{\circ} \mathrm{C}$. The galvanostatic deposition process was controlled by a constant current source (6220-DC current source, KEITHLEY-TEKTRONIX Inc., Beaverton, OR, USA) at $30 \mathrm{~mA}$ resulting in a current density of $10 \mathrm{~mA} / \mathrm{cm}^{2}$. The process time was about $750 \mathrm{~s}$. The $\mathrm{Pt}^{*}$ films were prepared with a thickness between 1 and $2 \mu \mathrm{m}$.

After preparation, the samples were heated in air in an oven (rapid high temperature furnace, Kanthal Super HT, SANDVIK AB, Hallstahammar, Sweden). The heating rate was $10 \mathrm{~K} / \mathrm{min}$, the dwell time $2 \mathrm{~h}$ and thereafter the samples were cooled down within the oven until the transfer temperature of approximately $120^{\circ} \mathrm{C}$ was reached. The annealing temperatures were $400,600,800$ and $1000{ }^{\circ} \mathrm{C}$.

The phase formation of the Pt films has been investigated by X-ray diffraction (XRD, Philips X'Pert PW3040/00, Co-Ka, PANalytical, Almelo, The Netherlands) in Bragg Brentano geometry.

Measurements of the electrical resistance were carried out by using the van der Pauw measurement method for thin films on planar substrates [24]. Several measurements were performed with constant current of 5 and $10 \mathrm{~mA}$ and changing the current direction for each measurement. The current was measured by a nanovoltmeter (2182A-Nanovoltmeter, KEITHLEY-TEKTRONIX, Inc., Beaverton, OR, USA).

Cross-sections of the film-substrate compounds were prepared by the focused ion beam technique (FIB, Zeiss $1540 \mathrm{XB}$ CrossBeam) and top down images were acquired by using scanning electron microscopy (SEM, Zeiss Ultra Plus) both from Carl Zeiss Microscopy GmbH, Jena, Germany.

Transmission electron microscopy (TEM, FEI Technai F30, FEI, Hillsboro, OR, USA) was applied to image the grain morphology. The local chemical composition was analyzed in the same instrument with energy dispersive X-ray spectroscopy (EDX, EDAX, Mahwah, NJ, USA). Additional to conventional TEM imaging bright field as well as high-angle annular dark field scanning modes (BF-/HAADF-STEM) were applied either to image the grain orientation or the chemical contrast (the imaging contrast used in each image is denoted in each case).

\section{Results}

\subsection{Phase Formation}

Figure 1 shows the results of the XRD measurements of the $\mathrm{Pt}^{*}$ films with $\mathrm{Ti}, \mathrm{W}, \mathrm{Ta}, \mathrm{Cr}$ or Pt seed layer in the as-deposited state (denoted as RT) and after the annealing steps.

In all the films in the as-deposited state broad peaks can be seen, which are caused by the small grain size (see also cross-section images in Figures 3, 5, 7, 9 and 12 for the different material systems). All the peaks are shifted to higher angles as compared to the standard position (for stress-free bulk material) suggesting that the films are under tensile stresses. Only in the case of $\mathrm{Pt}^{*}$ on Ti this effect is less pronounced. As the samples are annealed, the peaks are clearly shifted to the Pt standard position and the peak intensity increases along with narrowing of the peaks. This can be attributed to grain growth as is also confirmed from the FIB-cut cross-section view of the films (see Section 3.2). The narrowing of the peaks upon annealing can be well appreciated from the exemplary $\mathrm{Pt} 111$ peak 
(intensity normalized for viewing) shown in the Figure $1 \mathrm{~b}$. Above $800{ }^{\circ} \mathrm{C}$, only a very small narrowing can be ascertained.
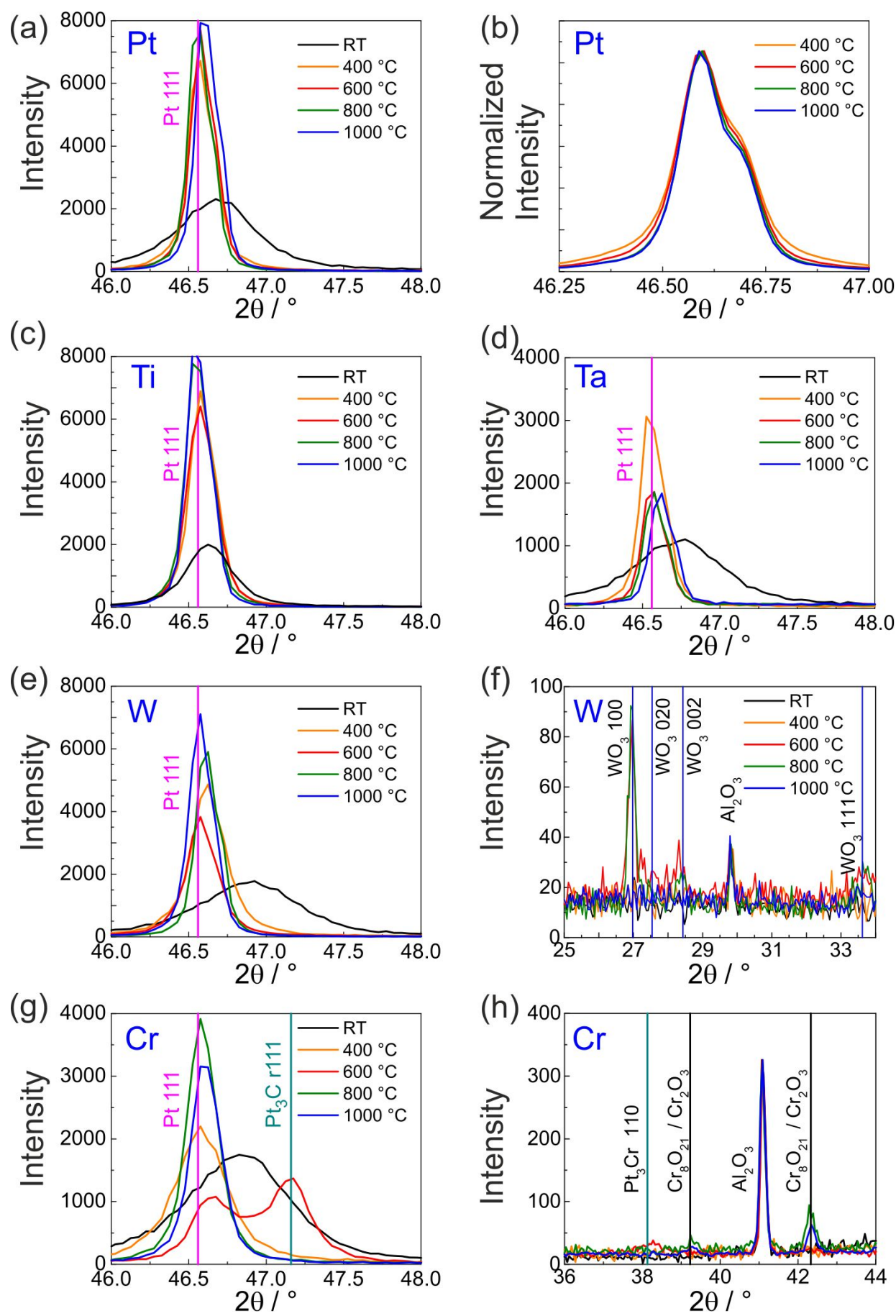

Figure 1. XRD diagrams of the $\mathrm{Pt}^{*}$ films on various seed layers in the as-deposited state (RT) and after annealing at $400,600,800$ or $1000^{\circ} \mathrm{C}$ in air. (a) Pt; (b) Pt with normalized intensities for a better comparability of the peak width; (c) Ti; (d) Ta; (e,f) W showing the $\mathrm{Pt}$ and $\mathrm{WO}_{3}$ reflexes; (g,h) $\mathrm{Cr}$ showing the $\mathrm{Pt}_{1} \mathrm{Pt}_{3} \mathrm{Cr}$ and $\mathrm{Cr}$ oxide reflexes.

In all the films, changes in the diffractogram are visible above $600{ }^{\circ} \mathrm{C}$. In case of $\mathrm{W}$ and $\mathrm{Cr}$ seed layer, clear oxide peaks belonging to $\mathrm{WO}_{3}$ (at 600 and $800{ }^{\circ} \mathrm{C}$, Figure 1f) and $\mathrm{Cr}_{8} \mathrm{O}_{21}$ or $\mathrm{Cr}_{2} \mathrm{O}_{3}$ (at 800 and $1000{ }^{\circ} \mathrm{C}$, Figure $1 \mathrm{~h}$ ) are indicated. However, in Ti and Ta (Figure 1c,d) the phase of the extra peaks 
(positions not shown here) could not be affirmatively established. In the $\mathrm{Pt} / \mathrm{Cr}$ film, $\mathrm{Pt}_{3} \mathrm{Cr}$ peaks were observed at $600{ }^{\circ} \mathrm{C}$ that disappear at higher temperatures (Figure 1g).

Figure 2 shows the normalized Pt 311 peak for all the as-deposited samples. The quantity of peak shift to higher angles as well as the increase in the peak broadening follow the order $\mathrm{Ti}<\mathrm{Pt} \approx \mathrm{Ta}<\mathrm{Cr} \approx \mathrm{W}$. This order corresponds to the increasing tensile stress and decreasing grain size in the as-deposited Pt films. Thus, Pt films in the as-deposited state on $\mathrm{Cr}$ and $\mathrm{W}$ had the smallest grain size. This is also re-confirmed from the cross-section images.

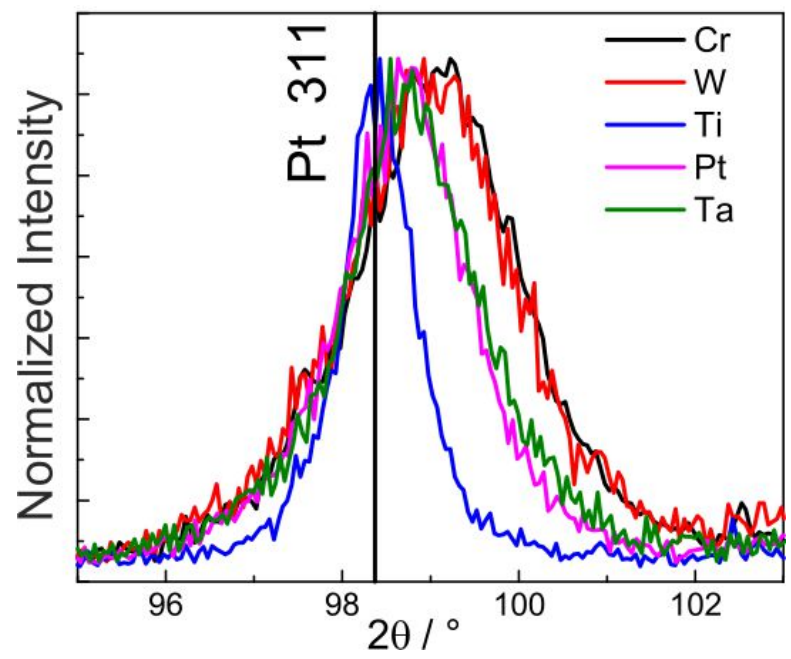

Figure 2. Comparison of the $\mathrm{Pt}$ peak width for the $\mathrm{Pt}^{*}$ films with the various seed layers in the as-deposited state.

\subsection{Film Morphology}

\subsubsection{Ti Seed Layer}

For the $\mathrm{Pt}^{*}$ film with Ti seed layer, Figure 3 summarizes the results of the SEM study of the surface and the cross-section images for the as-deposited state and after annealing at various temperatures. The images of the as-deposited samples (Figure 3a) show a $\mathrm{Pt}^{*}$ film with grains of the size between 10 and $100 \mathrm{~nm}$ and a clear interface to the Ti seed layer. A peculiarity of this film compared to the others is the growth of Pt whisker-like structures. These structures are formed if the electrodeposition is carried out in an electrolyte with low Pt content. This effect has been avoided for the subsequent depositions, as can be seen in the SEM images in the following sections.

The heat treatment at $400{ }^{\circ} \mathrm{C}$ leads to a clear grain growth within the $\mathrm{Pt}^{*}$ film whereas there are hardly any changes at the film surface (Figure 3b). The Ti film is still visible as a separate layer.

The high magnification SEM image of the $600{ }^{\circ} \mathrm{C}$ annealed sample (Figure 3c) shows that grains have further increased in size. The cross-section image demonstrates that the contrast of the grain boundaries has become significantly stronger. The Ti seed layer remains visible only below the extended grain in the center of the image. It has to be assumed that this annealing temperature is sufficient to activate the diffusion of $\mathrm{Ti}$ atoms along the $\mathrm{Pt}^{*}$ grain boundaries, as mentioned in the introduction (see Section 1). In contrast to this, after annealing at $800{ }^{\circ} \mathrm{C}$ (Figure $3 \mathrm{~d}$ ) the grain boundaries are hardly visible. Instead, a few narrow darker grains appear, which are extended nearly across the film thickness and, additionally, are present at some points between the $\mathrm{Pt}^{*}$ film and the substrate.

The most considerable changes are visible after annealing at $1000{ }^{\circ} \mathrm{C}$ (Figure 3e). The surface morphology has changed completely. The surface is much smoother, extended facets have formed and the whisker-like structures disappeared completely. The cross-section shows grains with $\mu \mathrm{m}$ 
size. However, the film has delaminated locally from the $\mathrm{Al}_{2} \mathrm{O}_{3}$ substrate. As for the $800{ }^{\circ} \mathrm{C}$ annealed sample, also dark grains are visible between the substrate and the film and locally within the $\mathrm{Pt}^{*}$ grains.

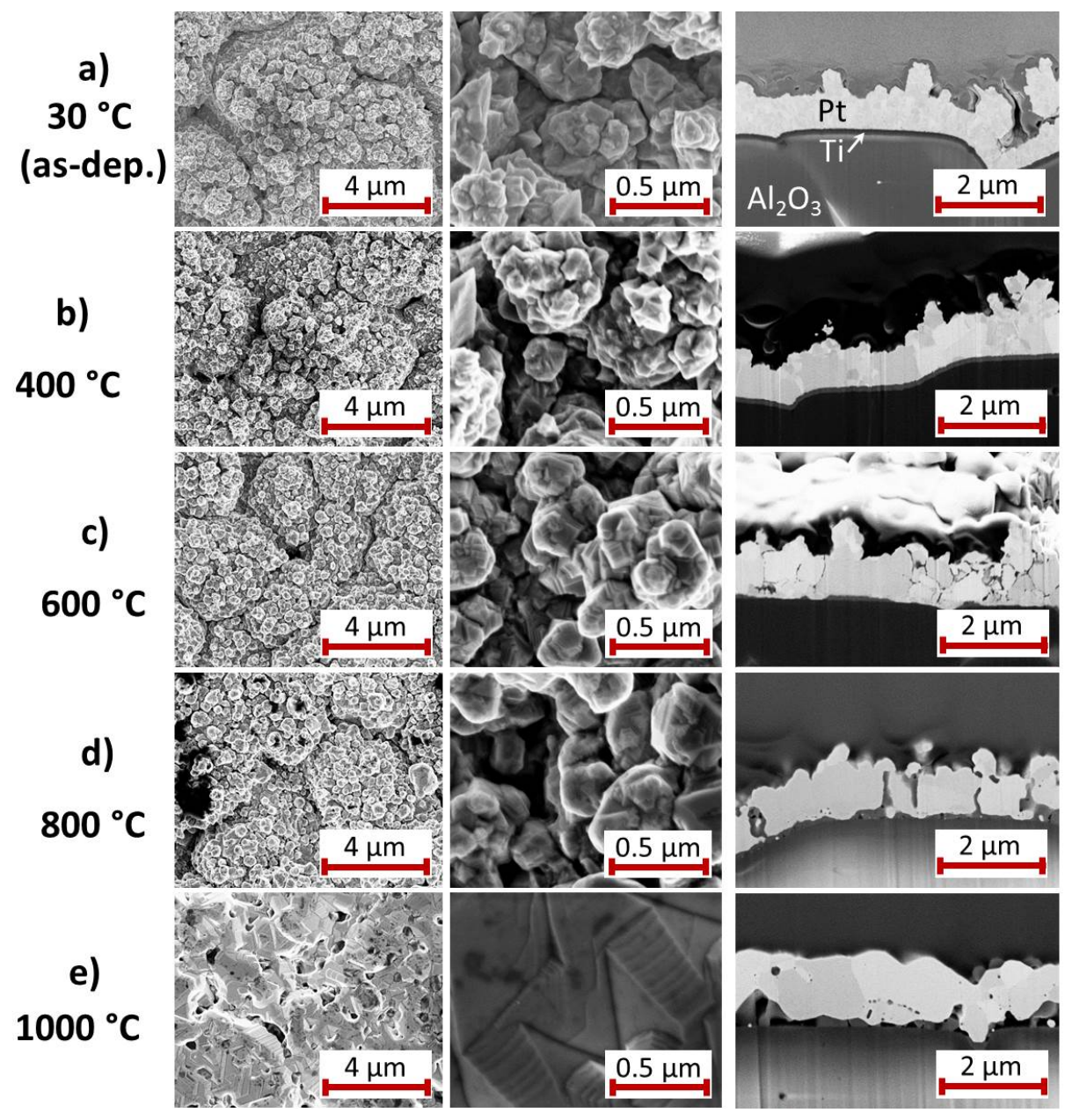

Figure 3. SEM images (InLens, $5 \mathrm{kV}, 3 \mathrm{~mm}$ working distance) with two different magnifications of the surface of the electrodeposited $\mathrm{Pt}^{*}$ film on Ti seed layer (a) after deposition and after annealing for $2 \mathrm{~h}$ in air at (b) 400; (c) 600; (d) 800 and (e) $1000{ }^{\circ} \mathrm{C}$. On the right hand side a SEM image (InLens, $3 \mathrm{kV}$, $5 \mathrm{~mm}$ working distance) of the film cross-section is presented.

To get more information about the film structure after the annealing process TEM studies have been performed for the $600{ }^{\circ} \mathrm{C}$ and $1000{ }^{\circ} \mathrm{C}$ annealed samples (Figure 4). The protection layer, which is labeled in Figure 4 and all further TEM images, is deposited within the FIB device prior to the cutting of the TEM lamella to protect the surface of the film during the preparation procedure.

For the $600{ }^{\circ} \mathrm{C}$ sample (Figure 4a) the EDX measurements prove that $\mathrm{Ti}$ is diffusing along the grain boundaries towards the sample surface. Already at this temperature Ti is oxidized. However, most of the $\mathrm{TiO}_{x}$ is still located at the interface between the $\mathrm{Al}_{2} \mathrm{O}_{3}$ substrate and the $\mathrm{Pt}$ film.

The sample annealed at $1000{ }^{\circ} \mathrm{C}$ (Figure $4 \mathrm{~b}$ ) shows extended $\mu \mathrm{m}$ size Pt grains and confirms the presence of several $100 \mathrm{~nm}$ sized pores between the film and the substrate, which are formed by the outwards diffusion of Ti. At several positions $\mathrm{TiO}_{x}$ grains are observed between the $\mathrm{Pt}^{*}$ film and the substrate and also between the $\mathrm{Pt}^{*}$ grains and they reach up to the film surface. Locally, $\mathrm{TiO}_{x}$ grains with a size in the range of $10-100 \mathrm{~nm}$ are embedded in the $\mathrm{Pt}^{*}$. Although a small solubility (1-5 at \% of Ti in Pt at $1000{ }^{\circ} \mathrm{C}$, depending on the source) for Ti in Pt is expected from the Pt-Ti phase diagram [25,26], we only find pure Pt grains without Ti. This can be explained by the high affinity of $\mathrm{Ti}$ for $\mathrm{O}$ so that it is oxidized instead of being solved within the $\mathrm{Pt}$ matrix. The Ti-O phase diagram 
shows that there are many different Ti oxide phases [27]. For us it was not possible to determine which phase or which mixture of phases has formed.
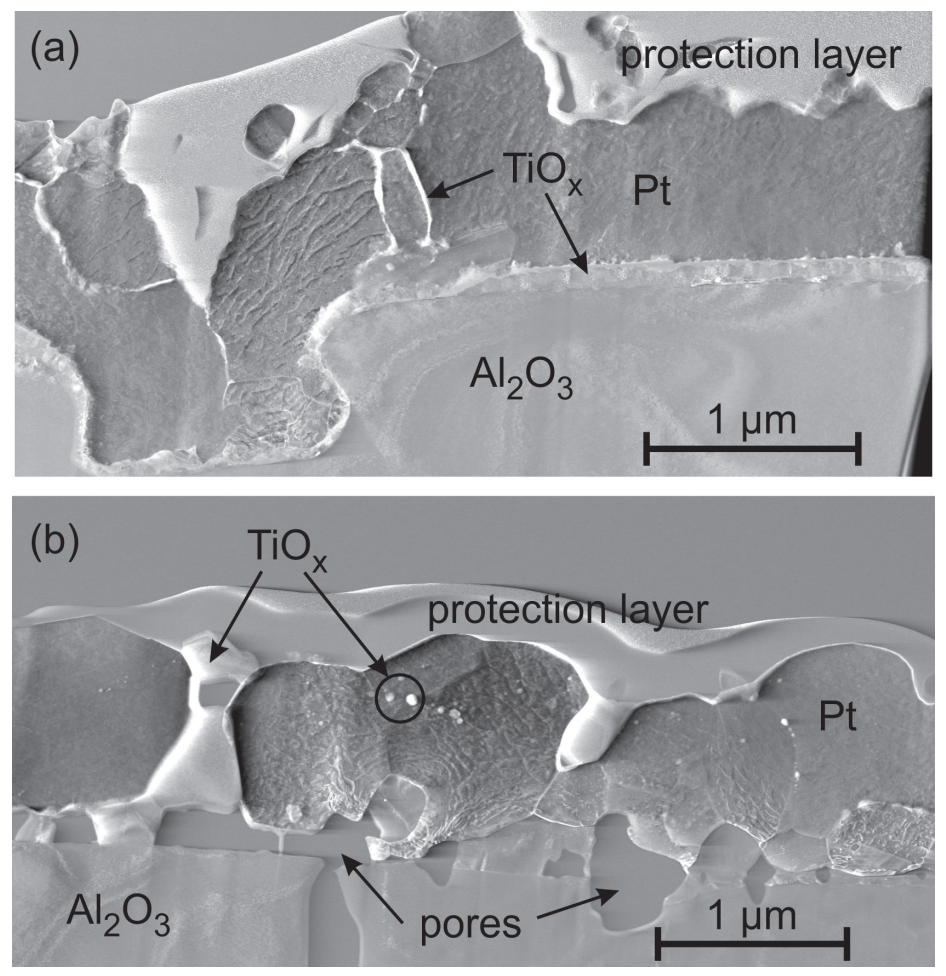

Figure 4. STEM image (grain orientation contrast) of the $\mathrm{Pt}^{*}$ film with Ti seed layer after annealing (a) at $600{ }^{\circ} \mathrm{C}$ and (b) at $1000{ }^{\circ} \mathrm{C}$ in air.

\subsubsection{W Seed Layer}

The behavior of the $\mathrm{Pt}^{*}$ film on $\mathrm{W}$ seed layer (Figure 5) during the annealing process is different to that observed on Ti.

Comparable to the Ti sample, after deposition (Figure 5a) the $\mathrm{Pt}^{*}$ film is very fine grained (grains with a few tens of nm size) with a smooth surface and the separate $W$ film is clearly visible. Furthermore, the heat treatment at $400{ }^{\circ} \mathrm{C}$ leads to a strong Pt grain growth (Figure 5b). The cross-section image, however, indicates that the $\mathrm{Pt}^{*}$ layer starts to delaminate from the $\mathrm{W}$ layer at this temperature. Additionally, the seed layer possesses a two-layer structure with a brighter lower and a darker upper layer. The total thickness of the seed layer has slightly increased.

In contrast to this, after annealing at $600{ }^{\circ} \mathrm{C}$, the seed layer has increased its thickness to approximately three times the thickness of the former $\mathrm{W}$ layer (Figure $5 \mathrm{c}$ ). Metallic tungsten gets oxidized at temperatures above $400{ }^{\circ} \mathrm{C}$ [28]. The bilayer structure of the $\mathrm{W}$ seed film after the heat treatment at $400{ }^{\circ} \mathrm{C}$ can be explained by the initiation of the oxidation whereas at $600{ }^{\circ} \mathrm{C}, \mathrm{W}$ is oxidized completely. The density of the formed $\mathrm{WO}_{3}$ is much smaller than that of metallic $\mathrm{W}\left(6.47 \mathrm{~g} / \mathrm{cm}^{3}\right.$ compared to $19.3 \mathrm{~g} / \mathrm{cm}^{3}$ ). In $\mathrm{WO}_{3}$ the volume per $\mathrm{W}$ atom is therefore about three times as high as for the $\mathrm{W}$ film, leading to the observed increase in film thickness. The origin of the oxygen for the formation of $\mathrm{WO}_{3}$ will be discussed in Section 4 .

To answer the question whether the $\mathrm{W}$ seed layer oxidizes from the substrate or the $\mathrm{Pt}^{*}$ film side, a TEM investigation with EDX analysis was carried out for the $400{ }^{\circ} \mathrm{C}$ sample. The HAADF STEM image (chemical contrast) in Figure 6 clearly shows the bilayer structure of the seed layer as well as a large gap between the seed layer and the $\mathrm{Pt}^{*}$ film. The EDX analysis reveals that the upper part of the seed layer is composed of $\mathrm{WO}_{3}$, which means that the oxidation occurs from the top side. 


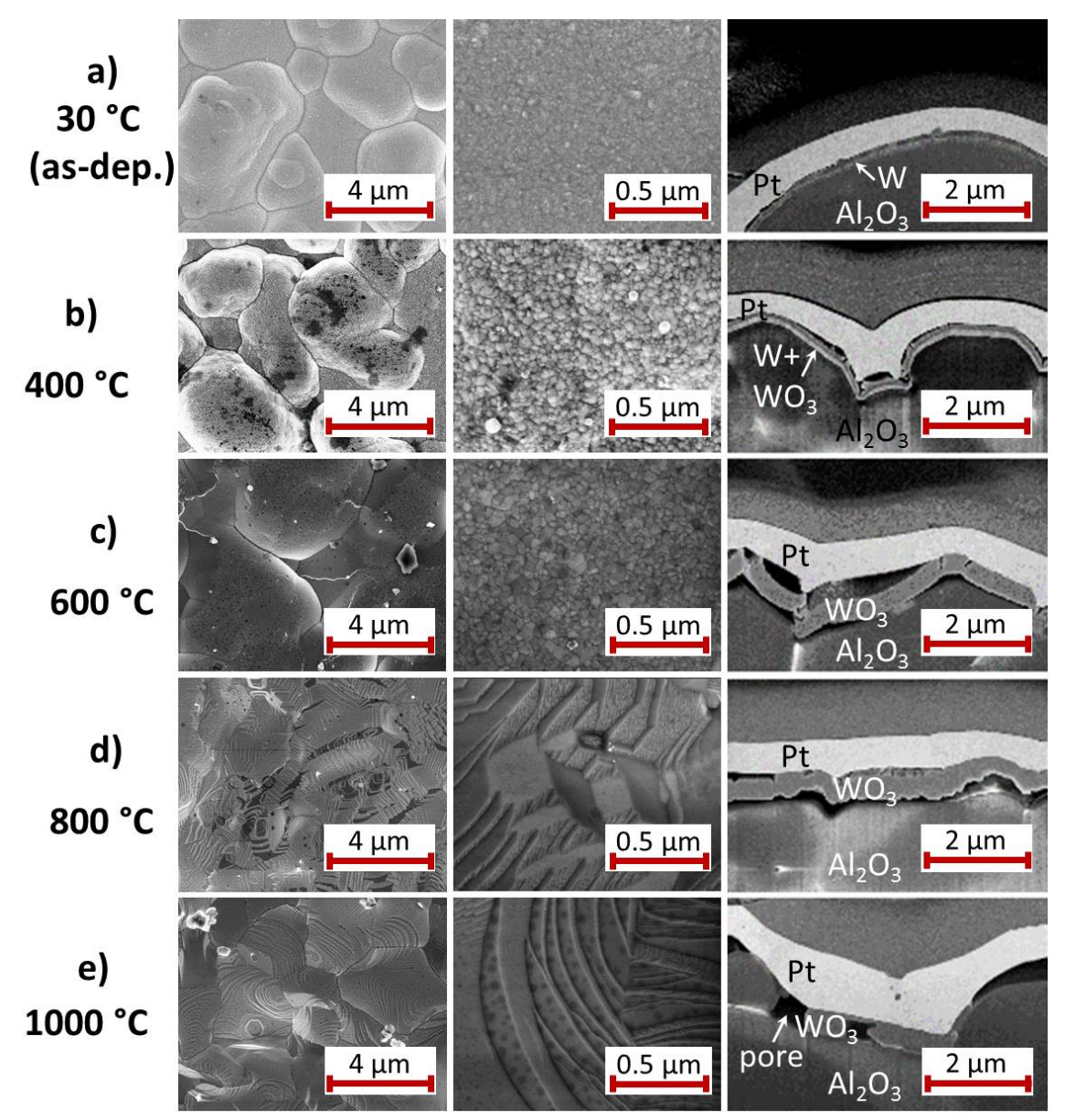

Figure 5. SEM images (InLens, $5 \mathrm{kV}, 3 \mathrm{~mm}$ working distance) with two different magnifications of the surface of the electrodeposited $\mathrm{Pt}^{*}$ film on $\mathrm{W}$ seed layer (a) after deposition and after annealing for $2 \mathrm{~h}$ in air at (b) 400; (c) 600; (d) 800 and (e) $1000{ }^{\circ} \mathrm{C}$. On the right hand side a SEM image (InLens, $3 \mathrm{kV}$, $5 \mathrm{~mm}$ working distance) of the film cross-section is presented.

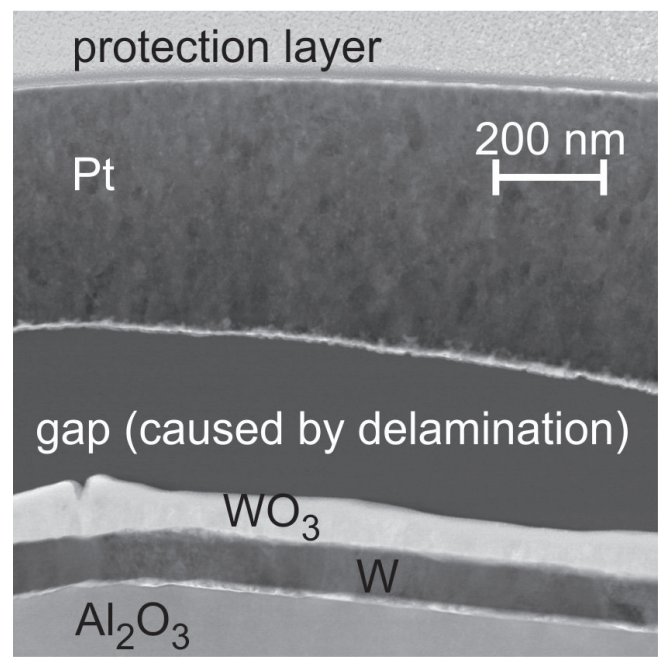

Figure 6. HAADF STEM image (chemical contrast) of the Pt* film on $\mathrm{W}$ seed layer after annealing at $400{ }^{\circ} \mathrm{C}$ in air. Due to the high thickness of the TEM lamella the absorption of the electrons in the $\mathrm{Pt}^{*}$ and $\mathrm{W}$ layers plays an important role leading to the dark appearance of $\mathrm{W}$ and $\mathrm{Pt}$ and to the brighter appearance of the $\mathrm{WO}_{3}$ layer and $\mathrm{Al}_{2} \mathrm{O}_{3}$ substrate. 
After annealing at $600{ }^{\circ} \mathrm{C}$ the $\mathrm{Pt}^{*}$ film is strongly delaminated. It appears that its shape does not correlate any more with the huge roughness of the substrate, but that instead this morphology is leveled out. The driving force for this behavior might be the resulting decrease of surface energy. Large grains ( $\mu \mathrm{m}$ size) have formed and a contrast indicating smaller grains is only visible where the film is bent outwards. At those positions heating of the sample leads to compressive stress. This can be reduced by the formation of small grains, since a large density of grain boundaries allows reduction of the mechanical stress.

After annealing at $800{ }^{\circ} \mathrm{C}$ (Figure 5d) and $1000{ }^{\circ} \mathrm{C}$ (Figure 5e) large flat planes are observed at the sample surface and clear facets have formed. The formation of these facets occurs at lower temperatures as compared to the Ti seed layer. Especially after the $1000{ }^{\circ} \mathrm{C}$ heat treatment the $\mathrm{WO}_{3}$ layer is not continuous any more but contains large pores, which can be explained with the sublimation of $\mathrm{WO}_{3}$. According to [29] the sublimation of $\mathrm{WO}_{3}$ starts at $750{ }^{\circ} \mathrm{C}$ and is significantly stronger above $900{ }^{\circ} \mathrm{C}$.

\subsubsection{Ta Seed Layer}

The morphology of the $\mathrm{Pt}^{*}$ film on Ta seed layer is presented in Figure 7. In contrast to the above described films, at RT there is hardly any contact between the Ta seed layer and the $\mathrm{Pt}^{*}$ film (Figure 7a). The heat treatment at $400{ }^{\circ} \mathrm{C}$ (Figure $7 \mathrm{~b}$ ) locally enlarges the size of these gaps. Only at individual points there is a contact between the $\mathrm{Pt}^{*}$ and the Ta. Furthermore, the thickness of the Ta layer has increased and comparable to the $\mathrm{W}$ seed layer there is a clear contrast between an upper and lower part of the layer. At RT there is a fine grain structure (few tens of $\mathrm{nm}$ ) in the $\mathrm{Pt}^{*}$ film. After annealing at $400{ }^{\circ} \mathrm{C}$, large grains with $\mu \mathrm{m}$ size have formed.

Annealing the sample at $600{ }^{\circ} \mathrm{C}$ leads to a completely different microstructure (Figure 7c). In the upper region, there are large $\mathrm{Pt}$ grains. In the lower region there is a zone with grains in the size of $100 \mathrm{~nm}$. In places the separate seed layer is present and above this layer big gaps are visible. On the right hand side of the image the $100 \mathrm{~nm}$ sized grain zone is extended to the substrate and no seed layer is identifiable at this position. This indicates a diffusion of Ta atoms in the $\mathrm{Pt}^{*}$ film. In contrast to Ti, Ta has a much higher solubility in Pt. At $600{ }^{\circ} \mathrm{C}$ there is a solubility of about 15 at \% of Ta in Pt [30], which can explain the formation of the different grain morphology in the lower film region.

The TEM/STEM images and EDX measurements presented in Figure 8 confirm the dissolution of Ta in the $\mathrm{Pt}^{*}$ grains and the oxidation of Ta. The overview TEM image in Figure 8a illustrates the smaller grains in the lower region of the $\mathrm{Pt}^{*}$ film, whereas in the upper region large grains are present. The EDX results (Figure $8 \mathrm{~b}, \mathrm{c}$ ) confirm the diffusion of Ta into the $\mathrm{Pt}^{*}$ layer. Of course, this interdiffusion only takes place at positions with a direct contact between the $\mathrm{Pt}^{*}$ and the $\mathrm{Ta}$ film. At regions without a contact between the seed and the $\mathrm{Pt}^{*}$ layer, $\mathrm{Ta}$ is completely oxidized and above the pores between both layers there is pure Pt. The interdiffusion between Ta and $\mathrm{Pt}^{*}$ is restricted to the lower few $100 \mathrm{~nm}$ of the $\mathrm{Pt}^{*}$ film. There is no sharp transition between the Ta oxide and the $\mathrm{Pt}_{100-x} \mathrm{Ta}_{x}$ phase, but there is a fine grained transition zone. The composition of the Ta oxide is close to $\mathrm{Ta}_{2} \mathrm{O}_{5}$, which is the only well established equilibrium phase in the Ta-O phase system [31]. The density of $\mathrm{Ta}_{2} \mathrm{O}_{5}$ is about half that of $\mathrm{Ta}$ [32], which leads to a strongly increased layer thickness as is observed in the cross-section images.

In contrast to the other samples, the smooth sample surface with its facet like structure forms at lower temperatures $\left(600^{\circ} \mathrm{C}\right)$ as can be seen in the SEM images in Figure 7c.

After the heat treatment at $800{ }^{\circ} \mathrm{C}$ a two layer structure is visible (Figure $7 \mathrm{~d}$ ). The seed layer is continuously present and large grains exist in the $\mathrm{Pt}^{*}$ film. It has to be assumed that heating to higher temperatures than $600{ }^{\circ} \mathrm{C}$ favors the complete oxidation of the Ta instead of the diffusion into the Pt. At the interface between both layers locally large pores have formed. No further changes are observed for the annealing at $1000{ }^{\circ} \mathrm{C}$ (Figure 7e). 


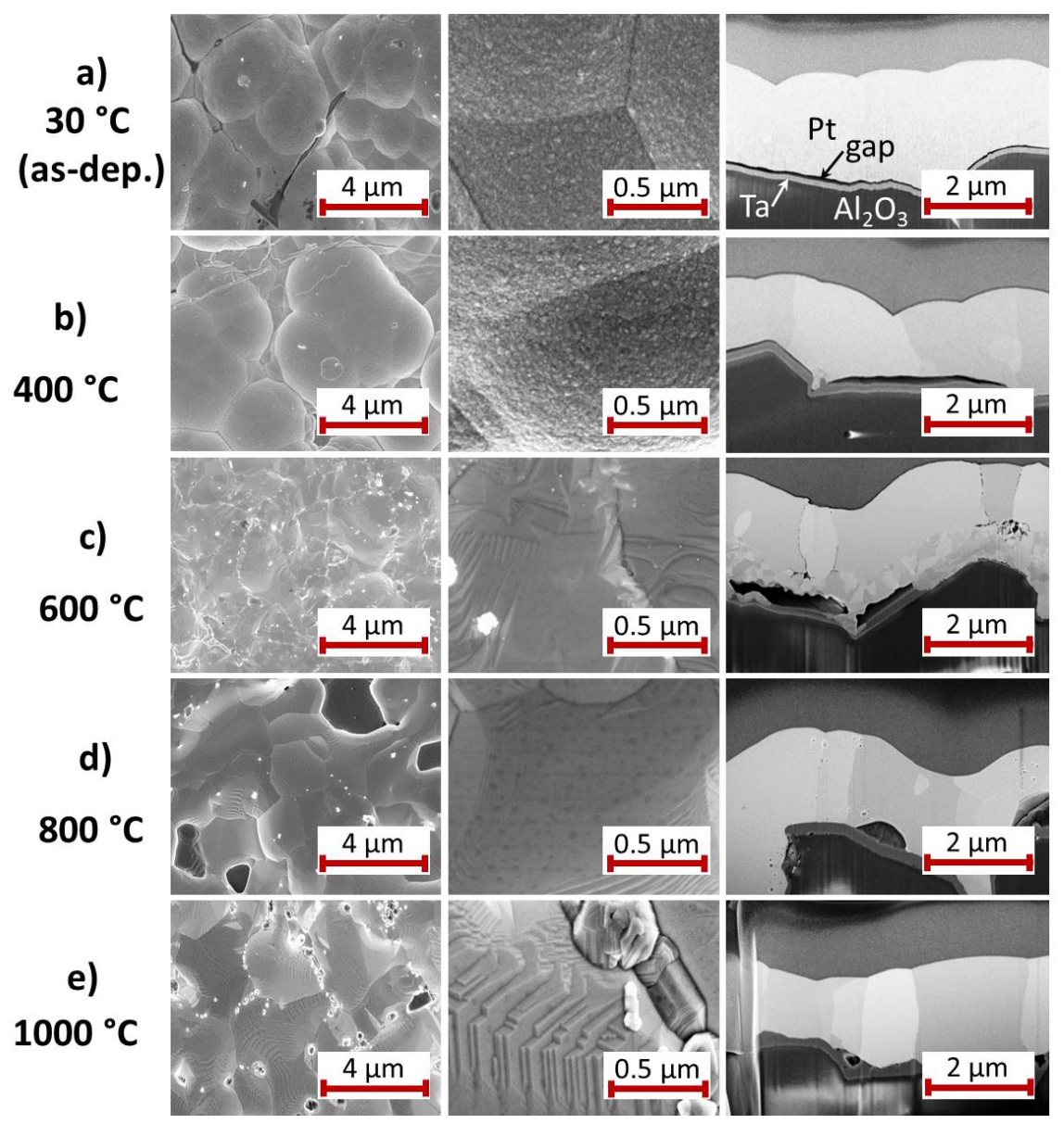

Figure 7. SEM images (InLens, $5 \mathrm{kV}, 3 \mathrm{~mm}$ working distance) with two different magnifications of the surface of the electrodeposited $\mathrm{Pt}^{*}$ film on Ta seed layer (a) after deposition and after annealing for $2 \mathrm{~h}$ in air at (b) 400; (c) 600; (d) 800 and (e) $1000^{\circ} \mathrm{C}$. On the right hand side a SEM image (InLens, $3 \mathrm{kV}$, $5 \mathrm{~mm}$ working distance) of the film cross-section is presented.

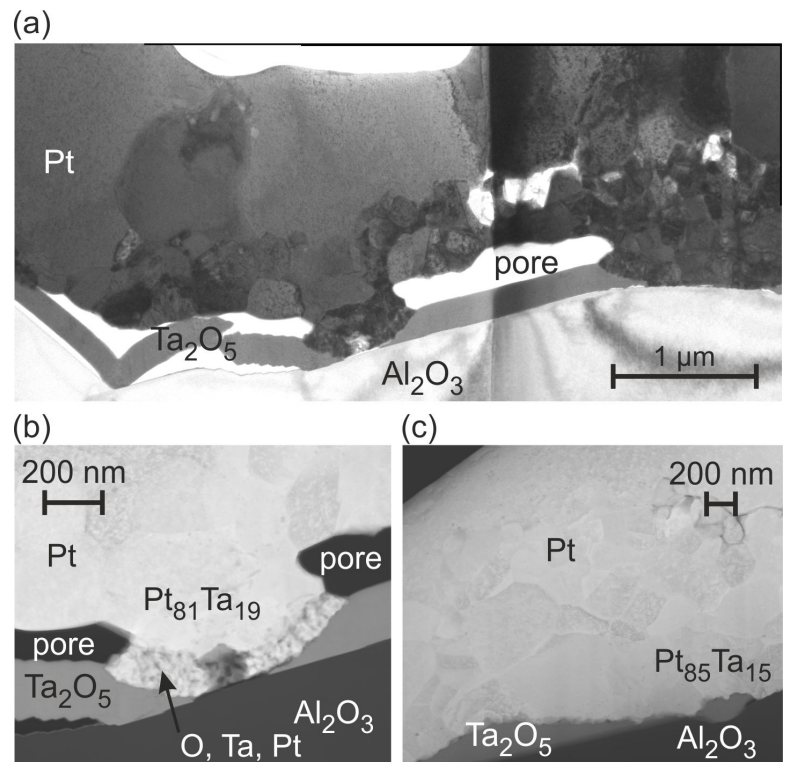

Figure 8. (a) TEM image of the $\mathrm{Pt}^{*}$ film on Ta seed layer after annealing at $600{ }^{\circ} \mathrm{C}$ in air; $(\mathbf{b}, \mathbf{c}) \mathrm{HAADF}$ STEM images (chemical contrast) with results of the EDX analysis. 


\subsubsection{Cr Seed Layer}

An overview of the surface morphology and cross-section images of the $\mathrm{Pt}^{*}$ film with $\mathrm{Cr}$ seed layer is given in Figure 9.

In contrast to the other seed layers there is no clear interface between the $\mathrm{Cr}$ and the $\mathrm{Pt}^{*}$ layer even at RT (Figure 9a). It appears that the $\mathrm{Cr}$ film is formed of fine columns. It has to be remarked that $\mathrm{Cr}$ dissolves as $\mathrm{Cr}(\mathrm{II})$ and $\mathrm{Cr}(\mathrm{III})$ ions in the ratio $\mathrm{Cr}(\mathrm{II}): \mathrm{Cr}(\mathrm{III}) \approx 7: 1$ by the sulfuric acid [33,34], which is part of the electrolyte used in the electrodeposition process. This reaction might lead to the observed grain structure in the $\mathrm{Cr}$ layer. A chemical analysis of the $\mathrm{Pt}^{*}$ film reveals that it contains no $\mathrm{Cr}$ so that the etched $\mathrm{Cr}$ atoms are not redeposited during the $\mathrm{Pt}^{*}$ deposition.

Heating the sample at $400{ }^{\circ} \mathrm{C}$ leads to a smoothening of the surface. The cross-section image hardly shows a grain growth inside the $\mathrm{Pt}^{*}$ layer (Figure $9 \mathrm{~b}$ ); a fine grained structure is still visible.

The sample morphology strongly changes during the annealing at $600{ }^{\circ} \mathrm{C}$ (Figure 9c). The surface images show large separated grains. The cross-section reveals some kind of three layer structure with about $100 \mathrm{~nm}$ sized grains in the middle $\mathrm{Pt}^{*}$ layer. At the surface there are brighter and darker grains and at the interface to the substrate a very inhomogeneous structure has formed with smaller grains.

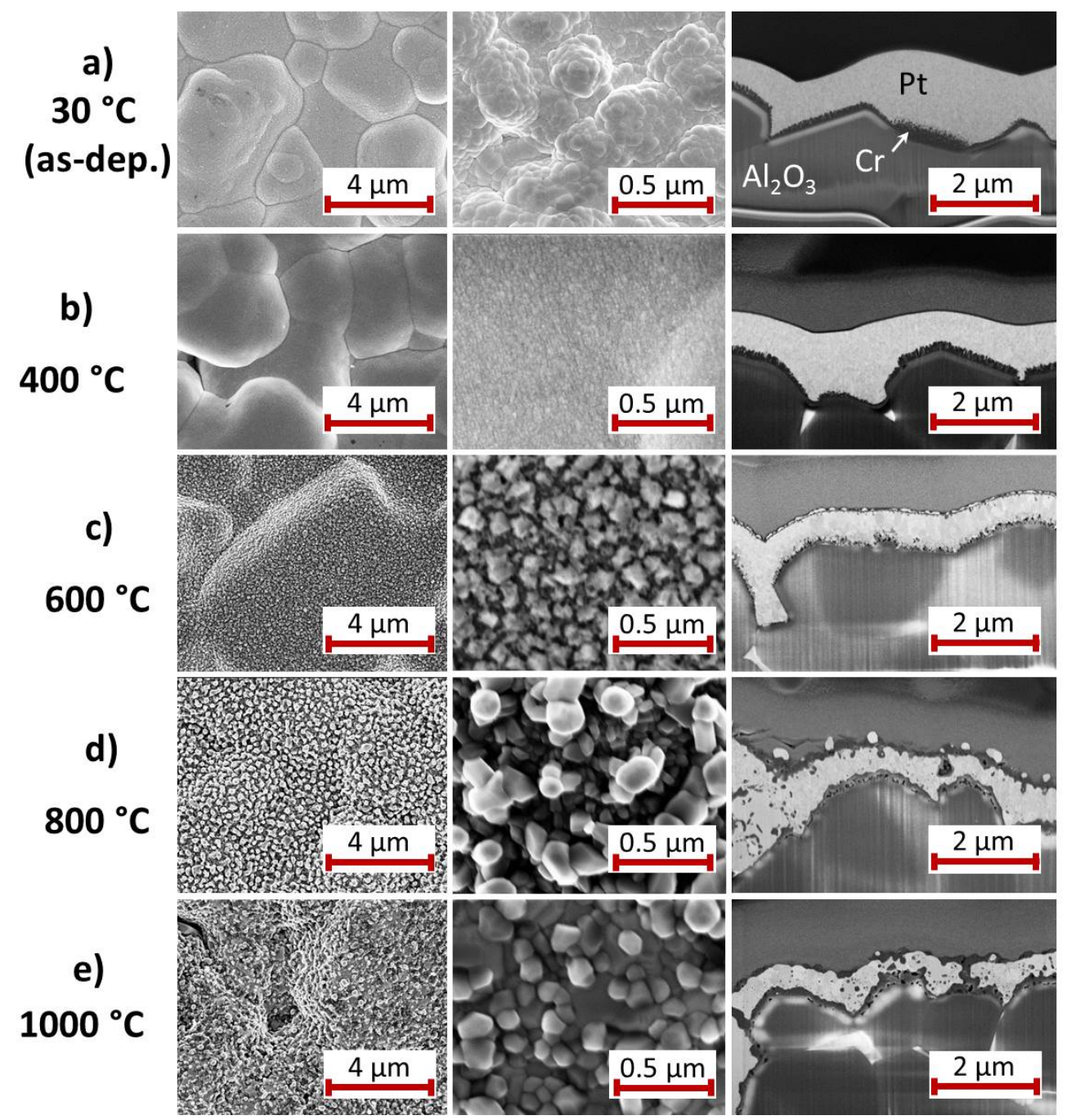

Figure 9. SEM images (InLens, $5 \mathrm{kV}, 3 \mathrm{~mm}$ working distance) with two different magnifications of the surface of the $\mathrm{Pt}^{*}$ film on $\mathrm{Cr}$ seed layer (a) after deposition and after annealing for $2 \mathrm{~h}$ in air at (b) 400; (c) 600; (d) 800 and (e) $1000{ }^{\circ} \mathrm{C}$. On the right hand side a SEM image (InLens, $3 \mathrm{kV}, 5 \mathrm{~mm}$ working distance) of the film cross-section is presented. 
Furthermore, for this sample a TEM and EDX analysis was done to investigate details of the layered microstructure (Figure 10). On top of the substrate a $\mathrm{Cr}$ oxide layer has formed. The determination of the ratio between $\mathrm{Cr}$ and $\mathrm{O}$ with EDX is challenging since $\mathrm{Cr}$ has EDX peaks at the same position like $\mathrm{O}$ and there exist a lot of different $\mathrm{Cr}-\mathrm{O}$ phases (see e.g., [35]). The calculated $\mathrm{Cr}$ :O ratio at the positions between substrate and the $\mathrm{Pt}^{*}$-Cr layer corresponds approximately to the $\mathrm{Cr}_{8} \mathrm{O}_{21}$ phase.

$\mathrm{Cr}$ was found across the whole thickness of the $\mathrm{Pt}^{*}$ layer. Most measured positions exhibit a composition between 22 and 28 at \% of $\mathrm{Cr}$, which fits to the $\mathrm{Pt}_{3} \mathrm{Cr}$ phase, which was also proven by the XRD measurements. According to the Pt-Cr phase diagram there is a solubility of more than 10 at \% of $\mathrm{Cr}$ in $\mathrm{Pt}$ [36] (there are also phase diagrams which state a solubility of more than 50 at \% $\mathrm{Cr}$ in $\mathrm{Pt}$ [37]). Locally a smaller $\mathrm{Cr}$ content was detected by the EDX measurements. However, we cannot distinguish if these are $\mathrm{Pt}$ grains with a smaller $\mathrm{Cr}$ content or if there is a superposition of a $\mathrm{Pt}$ matrix with $\mathrm{Pt}_{3} \mathrm{Cr}$ grains.

On top of the $\mathrm{Pt}_{3} \mathrm{Cr}$ film a thin $\mathrm{Cr}$ oxide layer is present, but with a lower $\mathrm{O}$ content (close to $\mathrm{Cr}_{2} \mathrm{O}_{3}$ ) as compared to the $\mathrm{Cr}$ oxide at the interface to the substrate (most likely $\mathrm{Cr}_{8} \mathrm{O}_{21}$ ). The phase $\mathrm{Cr}_{8} \mathrm{O}_{21}$ is an intermediate phase in the $\mathrm{CrO}_{3}$ decomposition process leading to the $\mathrm{Cr}_{2} \mathrm{O}_{3}$ final phase [38]. A possible explanation for the different $\mathrm{Cr}-\mathrm{O}$ phases at the interface to the substrate and at the surface might be that the oxidation reaction is advanced at the surface with the direct contact to the ambient $\mathrm{O}$ as compared to the inner $\mathrm{Cr}-\mathrm{O}$ below the $\mathrm{Pt} / \mathrm{Pt}_{3} \mathrm{Cr}$ film.

The EDX measurements reveal that the individual grains, which appear bright in the cross-section images on top of the film are composed of pure Pt. In contrast to the body of the film, which is composed of a Pt-Cr phase, the Pt grains at the surface do not contain $\mathrm{Cr}$.

After the heat treatment at $800{ }^{\circ} \mathrm{C}$ the grains at the surface have further increased in size and thus decreased in number (Figure 9d). The contrast between the grains inside the $\mathrm{Pt}^{*}$ layer has reduced. In contrast to the $600{ }^{\circ} \mathrm{C}$ sample a lot of dark features are present within the $\mathrm{Pt}^{*}$ film. The $\mathrm{Pt}^{*}$ layer is enclosed on both sides by a layer with a darker contrast, which corresponds most likely to the $\mathrm{CrO}_{x}$ layers. At the interface to the substrate pores have formed.

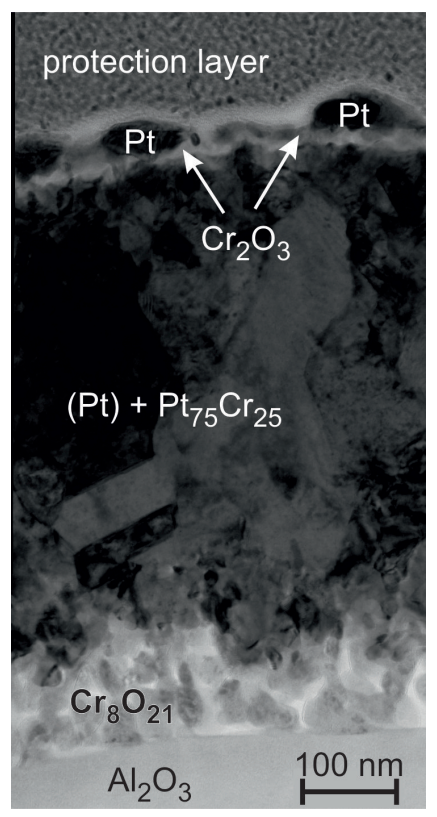

Figure 10. TEM image and EDX analysis of the $\mathrm{Pt}^{*}$ film on $\mathrm{Cr}$ seed layer after annealing at $600{ }^{\circ} \mathrm{C}$ in air. The $\mathrm{Cr}$-O phases are likely $\mathrm{Cr}_{2} \mathrm{O}_{3}$ at the upper part of the film and $\mathrm{Cr}_{8} \mathrm{Cr}_{21}$ at the interface to the substrate. 
The bright grains at the sample surface that are visible in the cross-sections are strongly reduced in number and size if the annealing temperature is increased to $1000{ }^{\circ} \mathrm{C}$ (Figure 9e). Obvious is the formation of pores at the interface to the substrate. The thin darker layers on top of the sample and at the interface to the substrate are still present. Locally there are connections between these two layers through the $\mathrm{Pt}^{*}$ film.

It is known that at higher temperatures (between 600 and $900{ }^{\circ} \mathrm{C}$ ) $\mathrm{Cr}_{2} \mathrm{O}_{3}$ forms with $\mathrm{O}_{2}$ gaseous $\mathrm{CrO}_{3}$ [39]. This behavior leads to the increasing number of pores if the sample is heated at increasingly higher temperatures. Figure 11 shows a STEM image (chemical contrast) of the sample annealed at $1000{ }^{\circ} \mathrm{C}$. The EDX measurements reveal a demixing of the Pt and $\mathrm{Cr}$. A pure Pt matrix is left in which spherical $\mathrm{Cr}$ oxide (likely $\mathrm{Cr}_{2} \mathrm{O}_{3}$ ) grains are embedded. The $\mathrm{Cr}$ oxide layer on top is not continuous. As for the $600{ }^{\circ} \mathrm{C}$ sample there is the compositional difference between the $\mathrm{Cr}$ oxide on top and that at the interface to the substrate.

In contrast to all other films, a facet like surface structure is not formed at all for this system.

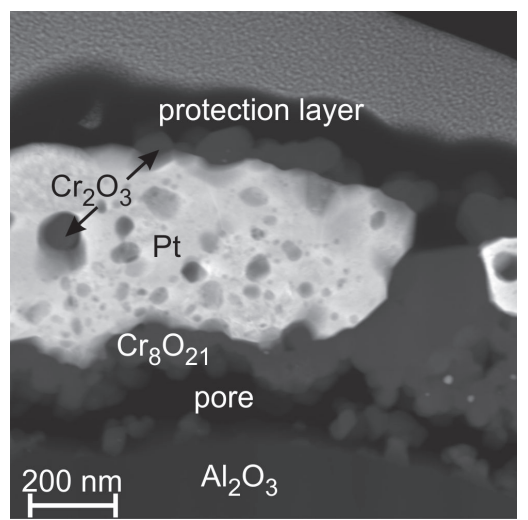

Figure 11. STEM image (chemical contrast) of the $\mathrm{Pt}^{*}$ film on $\mathrm{Cr}$ seed layer after annealing at $1000{ }^{\circ} \mathrm{C}$ in air.

\subsubsection{Pt Seed Layer}

Figure 12 summarizes the surface and cross-section images of the $\mathrm{Pt}^{*}$ film on a $\mathrm{Pt}$ seed layer.

In contrast to all the other bilayers, already at RT there is hardly any contact between the $\mathrm{Pt}$ film stack and the substrate (Figure 12a). A connection between the film and the substrate exists only at few distinct points, otherwise large gaps are visible because of partial delamination. Images of the cross-section with higher magnification reveal that there are many small pores at the interface between the $\mathrm{Pt}$ seed and the $\mathrm{Pt}^{*}$ layer. In both layers small grains (few tens of $\mathrm{nm}$ ) are visible.

The grains at the sample surface have slightly grown after annealing at $400{ }^{\circ} \mathrm{C}$ (Figure 12b). An interface between both $\mathrm{Pt}$ films is still visible. While grains in the $\mathrm{Pt}^{*}$ layer are extended over several $\mu \mathrm{m}$, those in the $\mathrm{Pt}$ film are significantly smaller (in the $100 \mathrm{~nm}$ range). The gaps between the $\mathrm{Pt}$ film and the substrate have become larger due to intrinsic stresses during the heat treatment. Locally there is a distance of several $100 \mathrm{~nm}$.

The heat treatment at $600{ }^{\circ} \mathrm{C}$ leads to a further growth of the grains at the sample surface and in the Pt seed layer (Figure 12c). The thickness of the former Pt seed layer increases at the expense of the thickness of the $\mathrm{Pt}^{*}$ layer. Still visible are pores at the grain boundaries of the $\mathrm{Pt}$ seed layer and between the $\mathrm{Pt}$ seed and the $\mathrm{Pt}^{*}$ layer.

After annealing at $800{ }^{\circ} \mathrm{C}$ the facet-like sample surface has developed (Figure 12d). Most of the grains in the $\mathrm{Pt}$ film are now extended over the whole film thickness, only few single smaller grains are present near to the interface to the substrate. With the coalescence of the seed and $\mathrm{Pt}^{*}$ layer most of the pores disappear.

Finally, the heat treatment at $1000^{\circ} \mathrm{C}$ leads to a Pt film with large grains. No bilayer structure is visible anymore (Figure 12e). Clear facets are present at the sample surface. 


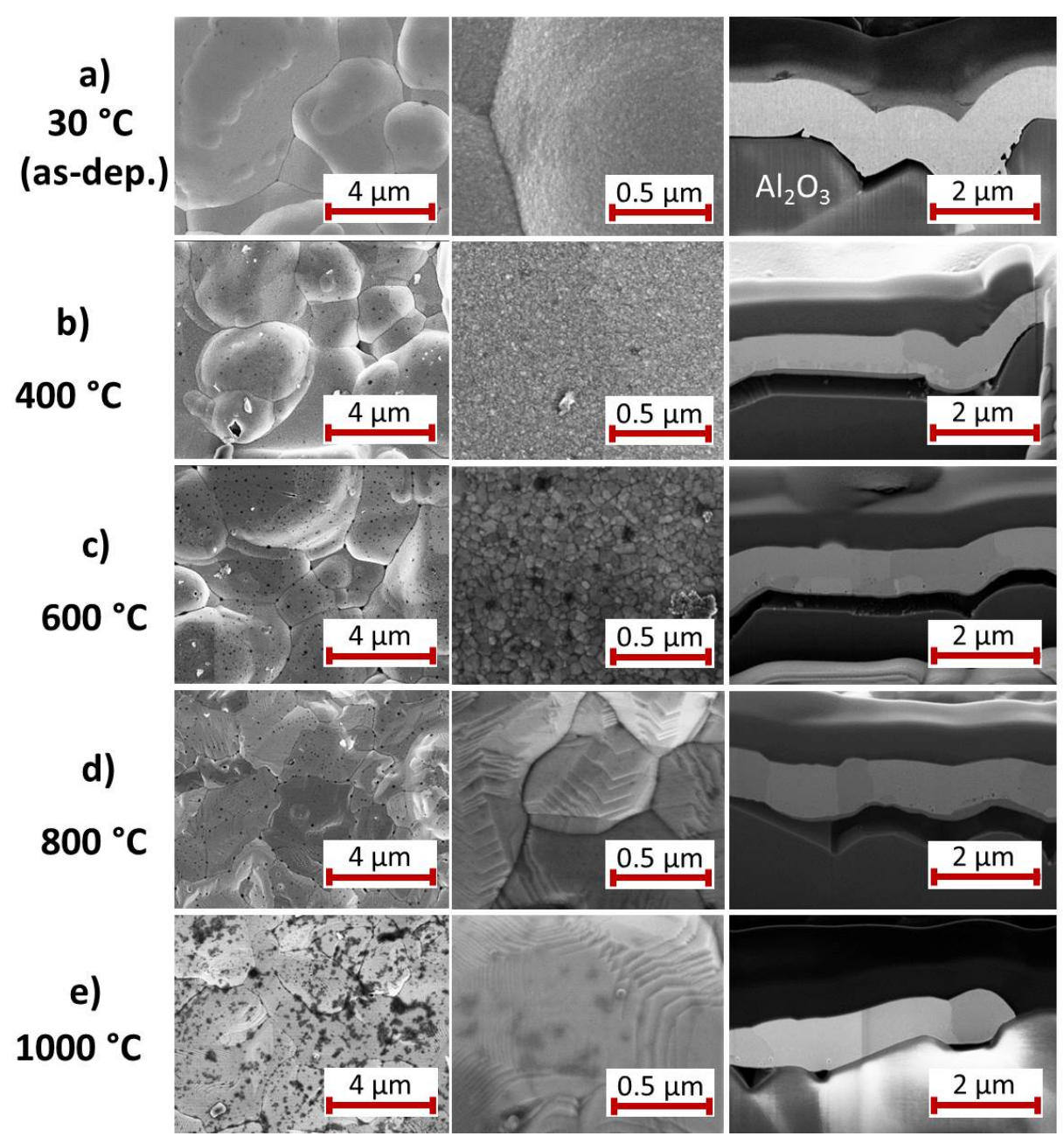

Figure 12. SEM images (InLens, $5 \mathrm{kV}, 3 \mathrm{~mm}$ working distance) with two different magnifications of the surface of the $\mathrm{Pt}^{*}$ film on $\mathrm{Pt}$ seed layer (a) after deposition and after annealing for $2 \mathrm{~h}$ in air at (b) 400; (c) 600; (d) 800 and (e) $1000{ }^{\circ} \mathrm{C}$. On the right hand side an SEM image (InLens, $3 \mathrm{kV}, 5 \mathrm{~mm}$ working distance) of the film cross-section is presented.

\subsection{Electrical Properties}

Since the films were investigated to evaluate their applicability as a material for the preparation of antennas on $\mathrm{Al}_{2} \mathrm{O}_{3}$ ceramics, besides the film morphology the electrical resistance is crucial. Figure 13 summarizes the values of the electrical resistance of the films with the different seed layers in the as-prepared state and after the different annealing steps. The values are all measured after the heat treatment at RT. Since all films possess a different "mean" film thickness (due to the extreme roughness of the substrate the declaration of a concrete film thickness is not possible) the absolute electrical resistance is not a practical value to describe and compare the different samples. Therefore, the change of the resistance with temperature is presented in such a way that the individual values $R$ are normalized to the value measured for the as-prepared state $R_{0}$. Each measurement point in Figure 13 represents the mean value of eight individual measurements with alternating direction of the electrical current. The standard deviation of the measurements for each point is less than $0.1 \%$ and with this smaller than the respective symbols in the plot. 


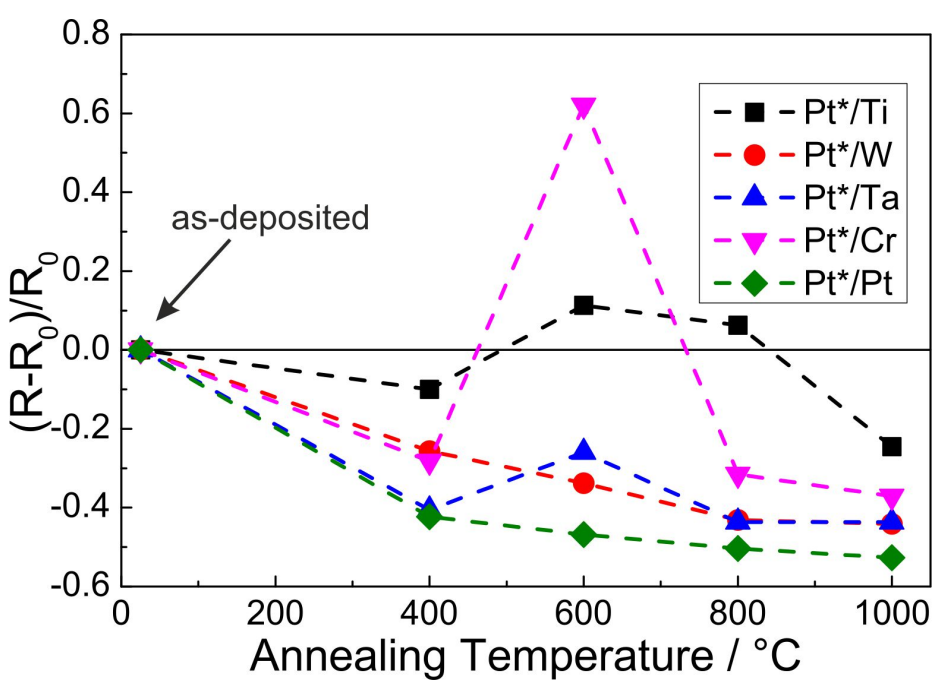

Figure 13. Relative electrical resistance of the $\mathrm{Pt}^{*}$-seed bilayers with respect to the individual resistance values $R_{0}$ measured for the as-deposited samples after the annealing steps.

The first annealing step at $400{ }^{\circ} \mathrm{C}$ leads to a decrease of the electrical resistance for all samples. The lowest change is observed for the Ti seed layer $(-10 \%)$ followed by the $\mathrm{W}$ and $\mathrm{Cr}$ seed layers $(\approx-25 \%)$. The strongest reduction occurs for the Ta and Pt seed layer $(\approx-40 \%)$.

Increasing the annealing temperature to $600{ }^{\circ} \mathrm{C}$ leads to a slight further reduction of the electrical resistance for the $\mathrm{W}$ and $\mathrm{Pt}$ seed layer $(\approx-35 \%$ and $\approx-45 \%$, respectively). For the Ti seed layer, the electrical resistance slightly increases above the RT value $(\approx+10 \%)$. Furthermore, for the Ta seed layer there is a slight increase compared to the value measured after the heat treatment at $400{ }^{\circ} \mathrm{C}$. In contrast to all other samples, the film with the $\mathrm{Cr}$ seed layer shows a strong increase to $+62 \%$ as compared to the RT value.

After the heat treatment at $800{ }^{\circ} \mathrm{C}$ the electrical resistance for the $\mathrm{Cr}$ sample strongly decreases to a value comparable to that measured after annealing at $400{ }^{\circ} \mathrm{C}(-32 \%)$. For all other samples there is a slight reduction as compared to the $600{ }^{\circ} \mathrm{C}$ value.

The heat treatment at $1000{ }^{\circ} \mathrm{C}$ leads to a further decrease of the electrical resistance for all samples. In summary we find a continuous decrease of the electrical resistance for the $\mathrm{W}$ and $\mathrm{Pt}$ seed layer. The other samples show an increase after annealing at $600{ }^{\circ} \mathrm{C}$ followed by a decrease at higher temperatures. The lowest relative value after annealing at $1000{ }^{\circ} \mathrm{C}$ is reached by the $\mathrm{Pt}^{*}-\mathrm{Pt}$ sample $(-53 \%)$, followed by the $\mathrm{Pt}^{*}-\mathrm{W}$ and $\mathrm{Pt}^{*}$-Ta sample $(-44 \%)$ and the $\mathrm{Pt}^{*}-\mathrm{Cr}$ sample $(-37 \%)$. The highest relative value is reached for the $\mathrm{Pt}^{*}$-Ti sample with a reduction compared to the as-deposited state of $-25 \%$.

\section{Discussion}

For the interpretation of the measurements one has to be aware that the different temperature steps were independent, i.e., for each annealing experiment a "new" sample in the as-deposited state was used. Therefore, effects that appear at a certain temperature-e.g., $600{ }^{\circ} \mathrm{C}$ seems to be a critical temperature step especially for interdiffusion effects-might not take place if the sample is directly heated $(10 \mathrm{~K} / \mathrm{min})$ to the higher temperatures. Other competing effects like oxidation of the seed layer material may then be favored.

We found a complete oxidation of the $\mathrm{Ti}, \mathrm{W}, \mathrm{Ta}$ and $\mathrm{Cr}$ seed layer. Either the seed layer oxide still exists as an individual layer (e.g., in the case of $\mathrm{WO}_{3}$ and to a large extend for $\mathrm{Ta}_{2} \mathrm{O}_{5}$ ) or the oxide grains are distributed between $\left(\mathrm{TiO}_{x}\right)$ or below, above and within $\left(\mathrm{CrO}_{x}\right)$ the $\mathrm{Pt}^{*}$ grains. The oxidation of the seed layer starts from the side of the $\mathrm{Pt}^{*}$ film; however the Pt film itself hardly contains any $\mathrm{O}$. To elucidate the origin of the $\mathrm{O}$ another experiment was performed. The sample with $\mathrm{W}$ barrier layer was chosen since it shows a clear bilayer structure consisting of $\mathrm{W}$ and $\mathrm{WO}_{3}$ after annealing at $400{ }^{\circ} \mathrm{C}$. 
In contrast to the first experiments with annealing under air conditions this time we chose a forming gas atmosphere. Figure 14 shows a cross-section image of the as-deposited $\mathrm{Pt}^{*} / \mathrm{W} / \mathrm{Al}_{2} \mathrm{O}_{3}$ sample (Figure 14a) together with the image of the same sample (lower $\mathrm{Pt}^{*}$ thickness because of different sample position) annealed in forming gas at $400{ }^{\circ} \mathrm{C}$ (Figure 14b) and the reference image after the annealing under air conditions (Figure 14c). The results clearly show that the annealing in forming gas does not lead to an oxidation of the $\mathrm{W}$ seed layer. The $\mathrm{W}$ grains are still visible as observed in the as deposited state. Therefore we conclude that during the annealing small cracks are formed in the $\mathrm{Pt}^{*}$ layer so that the gaps between the $\mathrm{Pt}^{*}$ layer and the $\mathrm{W}$ barrier are filled with air leading to the oxidation of the $\mathrm{W}$ layer. Obvious is the constant thickness of the $\mathrm{WO}_{3}$ and $\mathrm{W}$ layers. However, we find positions without a delamination gap between the $\mathrm{Pt}^{*}$ and the $\mathrm{W}$ film where no $\mathrm{W}$ oxide has formed (Figure 14d). This leads to the assumption that the $\mathrm{Pt}^{*}$ layer itself is dense and only local defects within the film act as $\mathrm{O}$ diffusion paths.

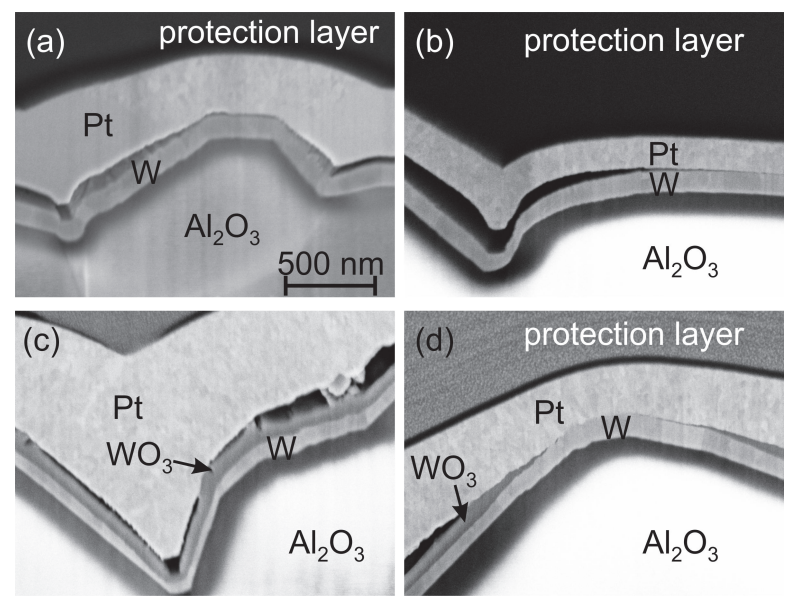

Figure 14. Cross-section images of a $\mathrm{Pt}^{*} / \mathrm{W} / \mathrm{Al}_{2} \mathrm{O}_{3}$ sample in (a) the as-prepared state and after annealing (b) in forming gas and (c) in air at $400{ }^{\circ} \mathrm{C}$ for $2 \mathrm{~h}$; (d) sample annealed in air showing a position where no $\mathrm{WO}_{3}$ has formed since there is no gap between the $\mathrm{Pt}^{*}$ and the barrier layer.

Nevertheless, all seed layers lead to a stable $\mathrm{Pt}$ film on the $\mathrm{Al}_{2} \mathrm{O}_{3}$. Although the Pt layer is locally delaminated from the substrate, the film does not peel off.

\subsection{Ti Seed Layer}

For the samples with the Ti seed layer the XRD measurements show a strong phase formation and grain growth after annealing at $400{ }^{\circ} \mathrm{C}$. The grain growth from RT to $400{ }^{\circ} \mathrm{C}$ leads to the observed reduction in the electrical resistance. The cross-section and STEM image of the sample annealed at $600{ }^{\circ} \mathrm{C}$ (Figures $3 \mathrm{c}$ and $4 \mathrm{a}$ ) reveal a strong grain boundary contrast in the $\mathrm{Pt}^{*}$ film caused by Ti and Ti oxide diffusion along these structures, which is also the origin of the increase of the electrical resistance for this annealing temperature. After the heat treatment at $800{ }^{\circ} \mathrm{C}$ hardly any grain boundary contrast is found, however few pores and $\mathrm{TiO}_{x}$ are left between some grains. All together this leads to the slight reduction in electrical resistance. The ongoing grain growth at higher temperatures is also visible in the further increased Pt XRD peaks and the lower electrical resistance.

\subsection{W Seed Layer}

In contrast to all other samples there is no reaction between the $\mathrm{W}$ seed and the $\mathrm{Pt}^{*}$ layer, which explains a similar development of the electrical resistance as compared to the $\mathrm{Pt}^{*} / \mathrm{Pt}$ bilayer. The oxidation of the $\mathrm{W}$ layer between 400 and $600{ }^{\circ} \mathrm{C}$ leads to a peeling of the $\mathrm{Pt}^{*}$ film but has no obvious influence on the grain growth of $\mathrm{Pt}^{*}$ with increasing temperature. The $\mathrm{WO}_{3}$ formation starts from the $\mathrm{Pt}$ side of the samples and not from the substrate interface. There is a continuous reduction of 
the electrical resistance in the whole temperature range. XRD measurements show $\mathrm{WO}_{3}$ reflexes for the 600 and $800^{\circ} \mathrm{C}$ annealing step, but not for the $100{ }^{\circ} \mathrm{C}$ sample. As noticed before, $\mathrm{WO}_{3}$ starts to sublime substantially above $900{ }^{\circ} \mathrm{C}$, which explains the large pores that are visible in the respective cross-section image and the disappearance of the $\mathrm{XRD}_{\mathrm{WO}}$ reflexes.

\subsection{Ta Seed Layer}

The XRD measurements show a strong grain growth at $400{ }^{\circ} \mathrm{C}$ but lower intensities at the higher temperatures. At $600{ }^{\circ} \mathrm{C}$ the cross-section image as well as the TEM investigation reveal a strong reaction between the Ta barrier and $\mathrm{Pt}^{*}$ layer, which explains the reduction in the Pt XRD peaks and the increased electrical resistance. The phase diagram Pt-Ta shows a high solubility of Ta in Pt of about 15 at $\%$ at $600{ }^{\circ} \mathrm{C}$ and several intermetallic phases.

The observed grain structures at $600{ }^{\circ} \mathrm{C}$ are not visible for the films annealed at higher temperatures. One reason might be that the high temperatures favor the oxidation instead of the interdiffusion of Ta and Pt. We assume that the Ta oxide formation occurs faster than the intermetallic phase formation and that at high temperatures the Ta layer has oxidized completely. The grain growth and the demixing then lead to the decreased electrical resistance.

\subsection{Cr Seed Layer}

Of all investigated seed layers we found the strongest reaction between the $\mathrm{Cr}$ seed and the $\mathrm{Pt}^{*}$ layer. Different at RT, compared to the other films, is the rough interface between the $\mathrm{Cr}$ and $\mathrm{Pt}^{*}$ layer. The phase formation and change in resistance upon annealing at $400{ }^{\circ} \mathrm{C}$ is comparable to the other samples. However, after annealing at $600{ }^{\circ} \mathrm{C}$ there are strong differences compared to the other samples: XRD shows a two phase state with only a small $\mathrm{Pt}$ peak and $\mathrm{a}_{3} \mathrm{Cr}$ peak beside it and the cross-section image reveals a small grained inhomogeneous structure. This explains the strong increase in electrical resistance. Cr diffuses through the whole Pt layer, which leads to the observed formation of the $\mathrm{Cr}$ oxide layer, not only at the bottom, but also on top of the $\mathrm{Pt} / \mathrm{PtCr}_{x}$ film.

Obviously, the annealing temperature of $400{ }^{\circ} \mathrm{C}$ is not sufficient for the $\mathrm{Pt}_{3} \mathrm{Cr}$ phase formation. On the other hand, at higher annealing temperatures of 800 and $1000{ }^{\circ} \mathrm{C}$, this phase is also not detected, although it is stable at higher temperatures according to the phase diagram [36]. For these temperatures, it has to be assumed that the oxidation kinetics of $\mathrm{Cr}$ dominates the $\mathrm{Pt}_{3} \mathrm{Cr}$ phase formation. The slightly higher electrical resistance of the sample after annealing at $1000{ }^{\circ} \mathrm{C}$ as compared to the others (besides the sample with $\mathrm{Ti}$ ) can be explained by the numerous $\mathrm{CrO}_{x}$ grains, which are distributed in the $\mathrm{Pt}$ layer and act as scattering centers.

\subsection{Pt Seed Layer}

In case of the $\mathrm{Pt}$ seed layer, the XRD measurements show, like for the other films, a strong grain growth and phase formation for the $400{ }^{\circ} \mathrm{C}$ sample. Of course, in contrast to the other materials, interdiffusion or intermetallic phase formation do not play a role. As stated above, the development of the electrical resistance of the $\mathrm{Pt}^{*} / \mathrm{Pt}$ film is quite similar to that of the $\mathrm{Pt}^{*} / \mathrm{W}$ system. In the case of $\mathrm{W}$, due to the formation of $\mathrm{W}$ oxide there is also no reaction with the $\mathrm{Pt}^{*}$ layer and there is hardly any contact between the $\mathrm{Pt}$ and the $\mathrm{WO}_{3}$ film, so that the development of the $\mathrm{Pt}^{*}$ grains takes place comparable to the $\mathrm{Pt}^{*} / \mathrm{Pt}$ sample.

\subsection{Evaluation of the Adhesion}

The FIB cuts of the $\mathrm{Pt}^{*}$ films with $\mathrm{Pt}$ seed layer show large pores between the substrate and the film. However, this film like all the others does not delaminate from the substrate and stays attached to it. Due to the high roughness of the substrate, at some positions "anchor-like" structures form as can be seen in the exemplary images in Figure 15 for samples with Pt (Figure 15a) or Ta (Figure 15b) seed layer. These "anchors" keep the film stuck to the substrate. 

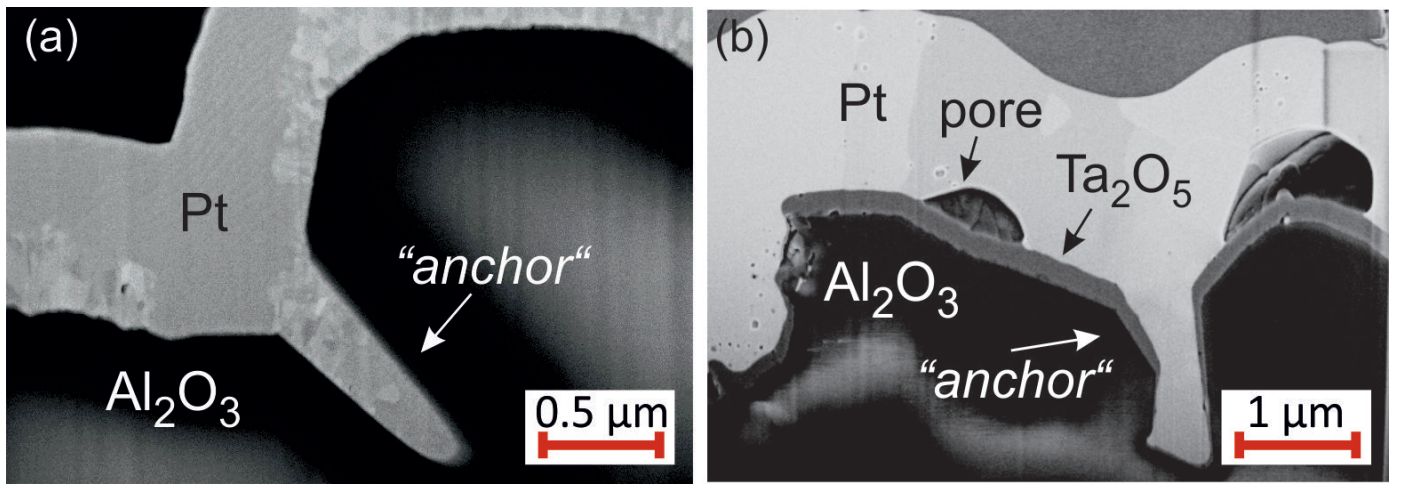

Figure 15. Example of anchor structures, which fix the $\mathrm{Pt}^{*}$ film to the $\mathrm{Al}_{2} \mathrm{O}_{3}$ substrate. (a) $\mathrm{Pt}$ seed layer, sample annealed at $400{ }^{\circ} \mathrm{C}$ in air and (b) Ta seed layer, sample annealed at $800{ }^{\circ} \mathrm{C}$ in air.

\section{Conclusions}

The investigations show several challenges for the application of seed layers for electrodeposited Pt films. On the one hand, there are interdiffusion effects; on the other hand, an oxidation of the applied seed materials takes place. Considering phase formation and electrical resistance, the $\mathrm{Pt}^{*} / \mathrm{Pt}$ system shows the best properties among the investigated materials. For all other systems, a complete oxidation of the seed layer is observed after the 2-h annealing process. If the oxide is distributed along the $\mathrm{Pt}$ grain boundaries $\left(\mathrm{TiO}_{x}\right)$ or in addition, also randomly within the Pt grains $\left(\mathrm{CrO}_{x}\right)$, the electrical properties are reduced. However, all investigated systems lead to a Pt film that is attached to the substrate and does not peel off.

Although cross-section images show only local contact between the $\mathrm{Pt}^{*} / \mathrm{Pt}$ system and the substrate, the film does not lift off, which we assume to be caused by the anchor-like structures.

As the films shall be used in SAW sensor technology working at high temperatures, it is essential that during the application, no phase transitions or oxidation effects take place. The authors especially notice these effects for the $600{ }^{\circ} \mathrm{C}$ samples. From our experiments, we conclude that prior to the application, the sample needs to be annealed at high temperatures to achieve a stable state.

Acknowledgments: The work was supported by German BMBF under Grant InnoProfile-Transfer 03IPT610Y. The authors would like to thank D. Bieberstein and T. Wiek for FIB cuts and TEM sample preparation. The authors also thank M. Uhlemann for support and discussion of the electrodeposition process and results.

Author Contributions: Erik Brachmann and Marietta Seifert conceived of and designed the experiments. Erik Brachmann prepared the films and conducted the SEM, electrical and part of the FIB measurements. Marietta Seifert performed the XRD and TEM/STEM/EDX measurements and the evaluation of the data. Gayatri K. Rane supported XRD measurements and analysis and the discussion of the data. Thomas Gemming supported TEM measurements and the discussion of the data. Siegfried B. Menzel supported measurements and the discussion of the data. The paper was written by Marietta Seifert and Erik Brachmann with the help of the other co-authors.

Conflicts of Interest: The authors declare no conflict of interest.

\section{References}

1. Thiele, J.A.; da Cunha, M.P. Platinum and palladium high-temperature transducers on langasite. IEEE Trans. Ultrason. Ferroelectr. 2005, 52, 545-549.

2. Moulzolf, S.C.; Frankel, D.J.; da Cunha, P.M.; Lad, R.J. High temperature stability of electrically conductive $\mathrm{Pt}-\mathrm{Rh} / \mathrm{ZrO}_{2}$ and Pt-Rh/HfO 2 nanocomposite thin film electrodes. Microsyst. Technol. 2014, 20, 523-531.

3. Lin C.M.; Yen, T.T.; Felmetsger, V.V.; Hopcroft, M.A.; Kuypers, J.H.; Pisano, A.P. Thermally compensated aluminum nitride Lamb wave resonators for high temperature applications. Appl. Phys. Lett. 2010, 97, 083501.

4. Ciftyurek, E.; Sabolsky, K.; Sabolsky, E.M. Platinum thin film electrodes for high-temperature chemical sensor applications. Sens. Actuators B Chem. 2013, 181, 702-714. 
5. Battistel, D.; Battaglin, G.; Daniele, S. Platinum/alumina thin films prepared by r.f. magnetron sputtering as platforms in voltammetric sensing. Sens. Actuators B Chem. 2014, 191, 143-151.

6. Weng, Y.C.; Rick, J.F.; Chou, T.C. A sputtered thin film of nanostructured Ni/Pt/ $\mathrm{Ti}$ on $\mathrm{Al}_{2} \mathrm{O}_{3}$ substrate for ethanol sensing. Biosens. Bioelectron. 2004, 20, 41-51.

7. Plessky, V.P.; Reindl, L.M. Review on SAW RFID Tags. IEEE Trans. Ultrason. Ferroelectr. 2010, 57, $654-668$.

8. Kang, A.L.; Zhang, C.R.; Ji, X.J.; Han, T.; Li, R.S.; Li, X.W. SAW-RFID enabled temperature sensor. Sens. Actuators A Phys. 2013, 201, 105-113.

9. Binder, A.; Bruckner, G.; Schobernig, N.; Schmitt, D. Wireless Surface Acoustic Wave Pressure and Temperature Sensor With Unique Identification Based on $\mathrm{LiNbO}_{3}$. IEEE Sens. J. 2013, 13, 1801-1805.

10. Saldanha, N.; Malocha, D.C. Pseudo-Orthogonal Frequency Coded Wireless SAW RFID Temperature Sensor Tags. IEEE Trans. Ultrason. Ferroelectr. 2012, 59, 1750-1758.

11. Fiaccabrino, G.C.; Koudelka-Hep, M. Thin-film microfabrication of electrochemical transducers. Electroanalysis 1998, 10, 217-222.

12. Khanna, V.K. Adhesion-delamination phenomena at the surfaces and interfaces in microelectronics and MEMS structures and packaged devices. J. Phys. D Appl. Phys. 2011, 44, 034004.

13. Cordill, M.J.; Moody, N.R.; Bahr, D.F. Quantifying improvements in adhesion of platinum films on brittle substrates. J. Mater. Res. 2004, 19, 1818-1825.

14. Bernhardt, G.; Silvestre, C.; le Cursi, N.; Moulzolf, S.C.; Frankel, D.J.; Lad, R.J. Performance of Zr and Ti adhesion layers for bonding of platinum metallization to sapphire substrates. Sens. Actuators B Chem. 2001, $77,368-374$.

15. Sreenivas, K.; Reaney, I.; Maeder, T.; Setter, N.; Jagadish, C.; Elliman, R.G. Investigation of Pt/Ti Bilayer Metallization on Silicon for Ferroelectric Thin-Film Integration. J. Appl. Phys. 1994, 75, 232-239.

16. Tiggelaar, R.M.; Sanders, R.G.R.; Groenland, A.W.; Gardeniers, J.G.E. Stability of thin platinum films implemented in high-temperature microdevices. Sens. Actuators A Phys. 2009, 152, 39-47.

17. Derniaux, E.; Kayser, P.; Gageant, C.; Sanchez, C.; Boivin, D. Effects of $\mathrm{TiO}_{x}$ physical vapor deposition parameters on the preferred orientation and adhesion of $\mathrm{Pt}$ films on gamma- $\mathrm{Al}_{2} \mathrm{O}_{3}$. J. Vac. Sci. Technol. A 2006, 24, 1540-1545.

18. Park, K.H.; Kim, C.Y.; Jeong, Y.W.; Kwon, H.J.; Kim, K.Y.; Lee, J.S.; Kim, S.T. Microstructures and Interdiffusions of $\mathrm{Pt} / \mathrm{Ti}$ Electrodes with Respect to Annealing in the Oxygen Ambient. J. Mater. Res. 1995, 10, 1790-1794.

19. Ehrlich, A.; Weiss, W.; Hoyer, W.; Gessner, T. Microstructural changes of Pt/Ti bilayer during annealing in different atmospheres - an XRD study. Thin Solid Films 1997, 300, 122-130.

20. Maeder, T.; Sagalowicz, L.; Muralt, P. Stabilized platinum electrodes for ferroelectric film deposition using Ti, Ta and Zr adhesion layers. Jpn. J. Appl. Phys. 1998, 37, 2007-2012.

21. Tisone, T.C.; Drobek, J. Diffusion in thin-film Ti-Au, Ti-Pd, and Ti-Pt couples. J. Vac. Sci. Technol. 1972, 9, 271-275.

22. Ciftyurek, E.; McMillen, C.D.; Sabolsky, K.; Sabolsky, E.M. Platinum-zirconium composite thin film electrodes for high-temperature micro-chemical sensor applications. Sens. Actuators B Chem. 2015, 207, 206-215.

23. Shelton, C.T.; Kotula, P.G.; Brennecka, G.L.; Lam, P.G.; Meyer, K.E.; Maria, J.P.; Gibbons, B.J.; Ihlefeld, J.F. Chemically Homogeneous Complex Oxide Thin Films Via Improved Substrate Metallization. Adv. Funct. Mater. 2012, 22, 2295-2302.

24. Pauw, L.J.v.d. A method of measuring the resistivity and Hall coefficient on lamellae of arbitrary shape. Philips Res. Rep. 1958, 13, 1-9.

25. Li, M.; Han, W.; Li, C. Thermodynamic assessment of the Pt-Ti system. J. Alloy. Compd. 2008, 461, $189-194$.

26. Biggs, T.; Cornish, L.A.; Witcomb, M.J.; Cortie, M.B. Revised phase diagram for the Pt-Ti system from 30 to 60 at.\% platinum. J. Alloy. Compd. 2004, 375, 120-127.

27. Wahlbeck, P.G.; Gilles, P.W. Reinvestigation of the phase diagram for the system titanium-oxygen. J. Am. Ceram. Soc. 1966, 49, 180-183.

28. Slade, P.G. Electrical Contacts: Principles and Applications, 2nd ed.; CRC Press: Boca Raton, FL, USA, 2013.

29. Lassner, E.; Schubert, W.-D. Tungsten: Properties, Chemistry, Technology of the Element, Alloys, and Chemical Compounds; Springer Science \& Business Media: New York, NY, USA, 2012.

30. Waterstrat, R.M. Analysis of selected alloys in the system Cr-Pd, Cr-Ru, V-Pd and Ta-Pt. J. Less-Common Met. 1981, 80, P31-P36. 
31. Garg, S.P.; Krishnamurthy, N.; Awasthi, A.; Venkatraman, M. The O-Ta (Oxygen-Tantalum) system. J. Phase Equilibr. 1996, 17, 63-77.

32. Reisman, A.; Holtzberg, F.; Berkenblit, M.; Berry, M. Reactions of the Group VB Pentoxides with Alkali

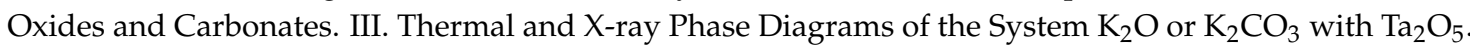
J. Am. Chem. Soc. 1956, 78, 4514-4520.

33. Drazic, D.M.; Popic, J.P. Dissolution of chromium in sulfuric acid. J. Serb. Chem. Soc. 2002, 67, 777-782.

34. Popic, J.P.; Drazic, D.M. Electrochemistry of active chromium-Part ii. Three hydrogen evolution reactions on chromium in sulfuric acid. Electrochim. Acta 2004, 49, 4877-4891.

35. Norby, P.; Christensen, A.N.; Fjellvag, H.; Nielsen, M. The crystal structure of $\mathrm{Cr}_{8} \mathrm{O}_{21}$ determined from powder diffraction data: Thermal transformation and magnetic properties of a chromium-chromatetetrachromate. J. Solid State Chem. 1991, 94, 281-293.

36. Baglin, J.E.E.; D'Heurle, F.M.; Zirinsky, S. Interaction between Cr and Pt films: New Cr-Pt Phases. J. Electrochem. Soc. 1978, 125, 1854-1859.

37. Aldinger, F. Thermodynamic models and data for pure elements and other endmembers of solutions. Group 6: Periodic system effects. CALPHAD: Comput. Coupling Phase Diagrams Thermochem. 1995, 19, 555-571.

38. Norby, P.; Fjellvag, H. Thermal Decomposition of Chromium(VI) Oxide; High Resolution In-Situ Powder Diffraction Studies of Mixed Valence Chromium Oxides; ESRF Experiment Report 01-01-263; 2003. Available online: http:/ /ftp.esrf.eu/pub/UserReports/21930_A.pdf (accessed on 9 January 2017).

39. Stanislowski, M.; Wessel, E.; Hilpert, K.; Markus, T.; Singheiser, L. Chromium Vaporization from High-Temperature Alloys: I. Chromia-Forming Steels and the Influence of Outer Oxide Layers. J. Electrochem. Soc. 2007, 154, A295-A306.

(c) 2017 by the authors; licensee MDPI, Basel, Switzerland. This article is an open access article distributed under the terms and conditions of the Creative Commons Attribution (CC-BY) license (http://creativecommons.org/licenses/by/4.0/). 